\title{
STRESS INCONTINENCE OF URINE IN THE FEMALE
}

\author{
By Terence Millin, M.Ch., F.R.C.S., \\ and \\ Charles D. Read, M.B. F.R.C.S.(E), F.R.A.C.S., F.R.C.O.G. \\ London
}

PART I

The distressing condition for which Sir Eardley Holland coined the term stress incontinence is variously known as orthostatic, exertional or diurnal incontinence.

The diagnosis presents little difficulty as a rule. The history varies according to the severity of the condition. In its mildest form the patient is conscious of an escape of a small quantity of urine in any movement which entails a rise of intraabdominal pressure when in the upright position - sneezing, coughing, walking up or down stairs. In its most severe form it may be evidenced by almost complete incontinence while in the upright position. Almost invariably there is adequate control while in the recumbent position, though we have observed a few advanced cases in which control has been inadequate even in this position if the coughing or sneezing has been violent.

It is important to differentiate between extreme precipitancy of micturition, i.e., urge incontinence, and the stress variety. Precipitancy may be the result of urinary infection giving rise to a basal cystitis. Such, of course, calls for appropriate antiseptic therapy, usually with sulpha drugs or the mandelates, according to the type of infection. Another troublesome cause of urge incontinence is a urethro-trigonitis unassociated with infection. These cases are frequently attributable to sexual misfits and other causes of pelvic congestion, and local therapy seldom avails, despite claims by some authors as to the advantages of urethral dilatation, diathermic coagulation, etc. The cause for the pelvic congestion should be sought and remedied, if possible. Operative procedures, to be discussed later, have no place in the treatment of such types of incontinence. It is equally essential to exclude neuropathies, e.g., tabes dorsalis and spina bifida, which may cause a somewhat similar syndrome. Surgical intervention in these is only too often followed by relapse, if not immediate failure.

True stress incontinence in the majority of cases is found in multiparae with a variable degree of genital prolapse, but the condition is encountered not infrequently in nulliparae about the menopausal age. It has long been recognized that little relationship exists between the degree of genital prolapse and the severity of the urinary incontinence. In fact, many women with an extreme degree of descensus have no stress incontinence, and conversely, patients exhibiting marked urinary loss may reveal little or no evidence of urethrocoele or cystocoele. On several occasions we have encountered stress incontinence which has developed after the successful repair of a prolapse in patients who previously had been completely continent of urine.

Many years ago Victor Bonney showed that by supporting the bladder neck on either side of the urethra by means of intravaginal digital pressure the involuntary escape of urine from a full bladder could be prevented. He deduced that the urinary loss resulted from a sagging of the bladder neck, due to stretching of the pubocervical fascia, and he concluded that the cure of the symptoms was dependent on the restoration of this fascial structure. In cases in which he failed to effect a cure by means of his buttress operation from below, he advocated a cystopexy by the abdominal approach. We have found Bonney's test difficult to apply, as it is hard to convince oneself that the digital pressure is not being exerted on the upper urethra when endeavouring to support the bladder neck by the intra-vaginal fingers. We have found that, by the use of long, rubber-covered forceps in place of the fingers, it is possible to support the bladder neck without exerting compression of the urethra, and by this means Bonney's contention can be easily verified.

Having established this point it appeared to one of us (T.M.) that radiological confirmation should not be difficult, and the technique about to be described was evolved. Many previous workers had essayed radiological studies, but little progress had been made and in 1946, Muellner, in an article on this subject, affirmed that neither endoscopic 
nor radiological studies had offered conclusive evidence as to the precise mechanism of the lesion. In this connection we must mention the painstaking studies of Kennedy of New York, who used distensible rubber bags which could be filled with radio-opaque media. By placing these in the urethra he claimed to demonstrate the presence of several urethral sphincters which he believed to play an important part in urinary control. $\mathrm{He}$ held that stress incontinence was the result of dysfunction of these sphincters, and stressed the importance of the sphincter surrounding the midurethra. The fact, however, that two-thirds of the urethra may be excised for malignant involvement without the subsequent development of incontinence would appear to disprove the importance of this structure. Moreover, the formation of a completely new urethra by either the trocarization method of Marion or by the vaginal flap method recently described by Couvelaire of Paris, in both of which complete continence is eventually obtained by the sole use of the bladder musculature, would appear to present strong confirmatory evidence that these so-called urethral sphincters play little part in urinary control. We have satisfied ourselves that in the interlacing fibres of the detrusor at the vesical outlet resides the chief mechanism of urinary control in the female.

\section{Technique of Cystography in Stress Incontinence}

A No. $20 \mathrm{~F}$ Malecot catheter is passed on a stilet into the bladder. The bladder is emptied, and by means of a syringe, 6-1o ozs. of ro per cent. solution of sodium iodide is introduced, and the catheter is spigotted. The patient then stands against a vertical $X$-ray screen with the tube centred on the upper border of the symphysis pubis. She is requested to take a short breath, and to remain immobile while the first exposure is made. The patient, still in the identical position, is then requested to strain down as in the act of defaecation, and a second exposure is made on the same film, i.e., a double exposure. The second exposure reveals the bladder neck in its position when the intra-abdominal pressure is raised, i.e., as in coughing, sneezing or straining. As an alternative method two separate films may be used-one exposure being made in the relaxed upright position and the other whilst straining. The films are superimposed for reading purposes. A study of many scores of these skiagrams reveals, as anticipated from the clinical studies, that in the normal woman not exhibiting stress incontinence there is no demonstrable descent of the bladder base, but in those suffering from such a urinary loss, there is a very appreciable lowering of the vesical outlet, and in advanced cases there is a funnelling of the exitus. Moreover, from a stud of the extent of this descent one can estimate the severity of the condition. In short, it is possibe to assess the degree of the incontinence fro $\mathrm{m}$ perusal of the skiagrams.

It can be appreciated that the presence of cystocoele without stress incontinence may give the radiographic appearance of apparent lowering of the bladder neck in an antero-posterior fil owing to the fact that the cystocoele descends with its radio-opaque contents. By taking films in the lateral or oblique positions the level of the cystocoele can be differentiated from that of the bladder neck. Lateral radiograms, owing to the density of the femora and pelvic bones, are le satisfactory in their definition than oblique pie. tures, with the tube directed through the obturatoo foramen. In these oblique films non-descent $\overrightarrow{Q f}$ the vesical outlet can be demonstrated where stres incontinence is absent. Figs. I-22 illustrate somie typical cystograms.

Having established to our satisfaction both clinically and radiographically that a descent $f$ the bladder neck is present in those patients wh exhibit stress incontinence, it became obvious th any operative intervention to cure the condition must aim at elevation of the bladder neck. must be remembered that we are not here 8 incerned with those patients who develop in tinence immediately after parturition and who cure can usually be effected by appropriate remedial exercises, and combined if necessary wiक faradic stimulation; neither are we considerim those minimal degrees of the condition which benefit often by fulguration of the bladder nect. We have under review those more advanced cases for which surgical intervention is sought, or $\overline{\text { in }}$ which the simpler remedies have failed. would stress that in all cases in which there is $\overrightarrow{a n}$ associated uterine or vaginal prolapse or both, the firsi procedure to be embarked upon is one which with cure the prolapse, but at the same time steps shoud be taken to elevate the bladder neck from below at the time of the vaginal repair.

\section{Operative Treatment of Stress \\ Incontinence}

Three methods of approach for the cure of the condition have been described and each method of approach exhibits many alternative procedures

(a) Vaginal approach.

(b) Abdominal approach.

(c) Combined abdomino-vaginal approach.

\section{Vaginal Operations}

(I) Colporrhaphy with special sub-urethr' repair of various types as described Bonney, Marion, Kelly, Kennedy, Davies and Wilfred Shaw. 

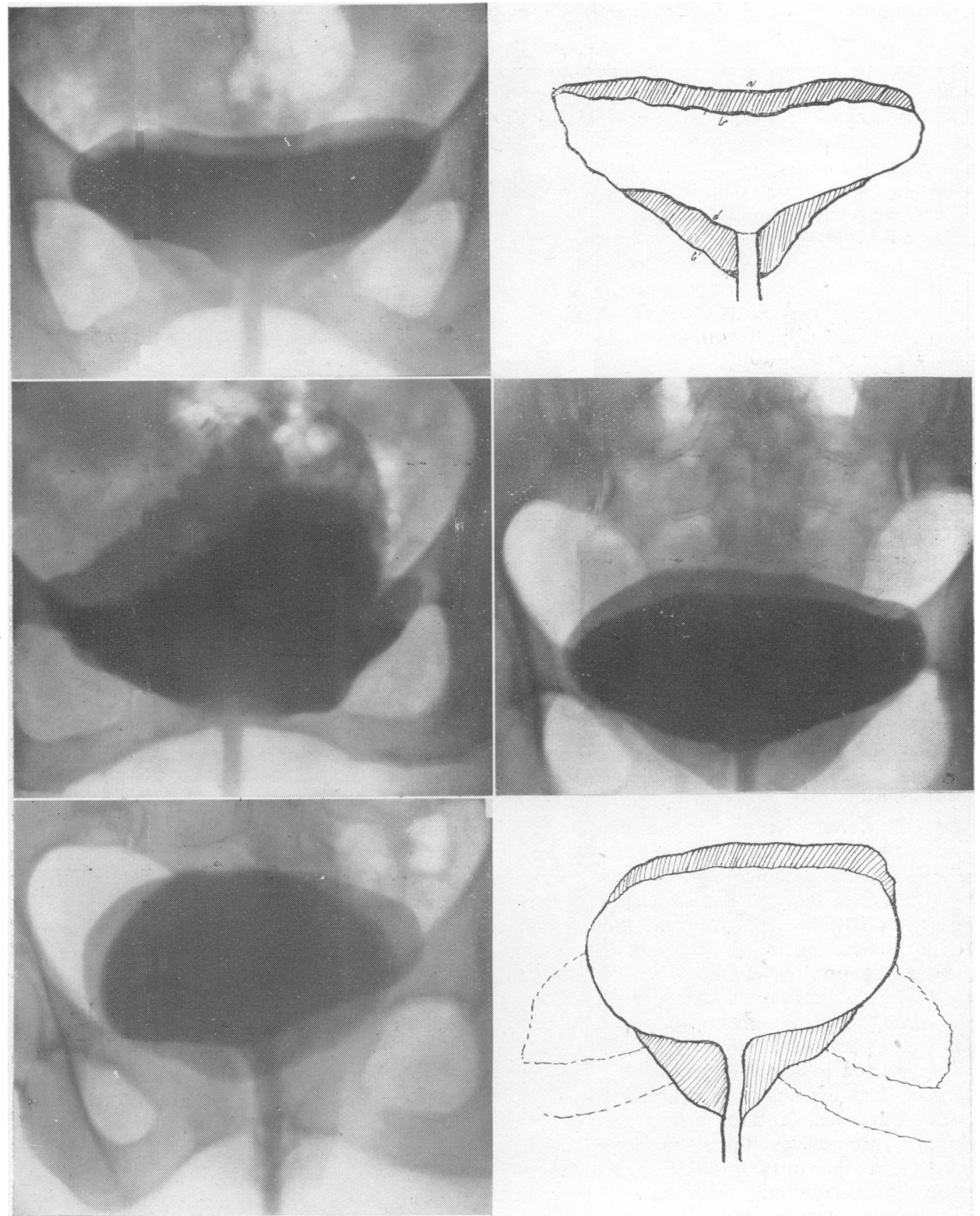

FIG. I.-Superimposed cystograms in patient with marked stress incontinence. Note marked lowering of bladder base in the position of strain (cf. Fig. 2).

FIG. 3.--Superimposed cystograms in patient with moderate genital prolapse without stress incontinence. Note the descent of the upper level of the bladder shadow on raising the intra-abdominal pressure but fixed position of the bladder base.

FIg. 5.- Superimposed cystograms in case of stress incontinence only partially relieved by vaginal repair. (Cure by Millin sling 14 months ago.) 

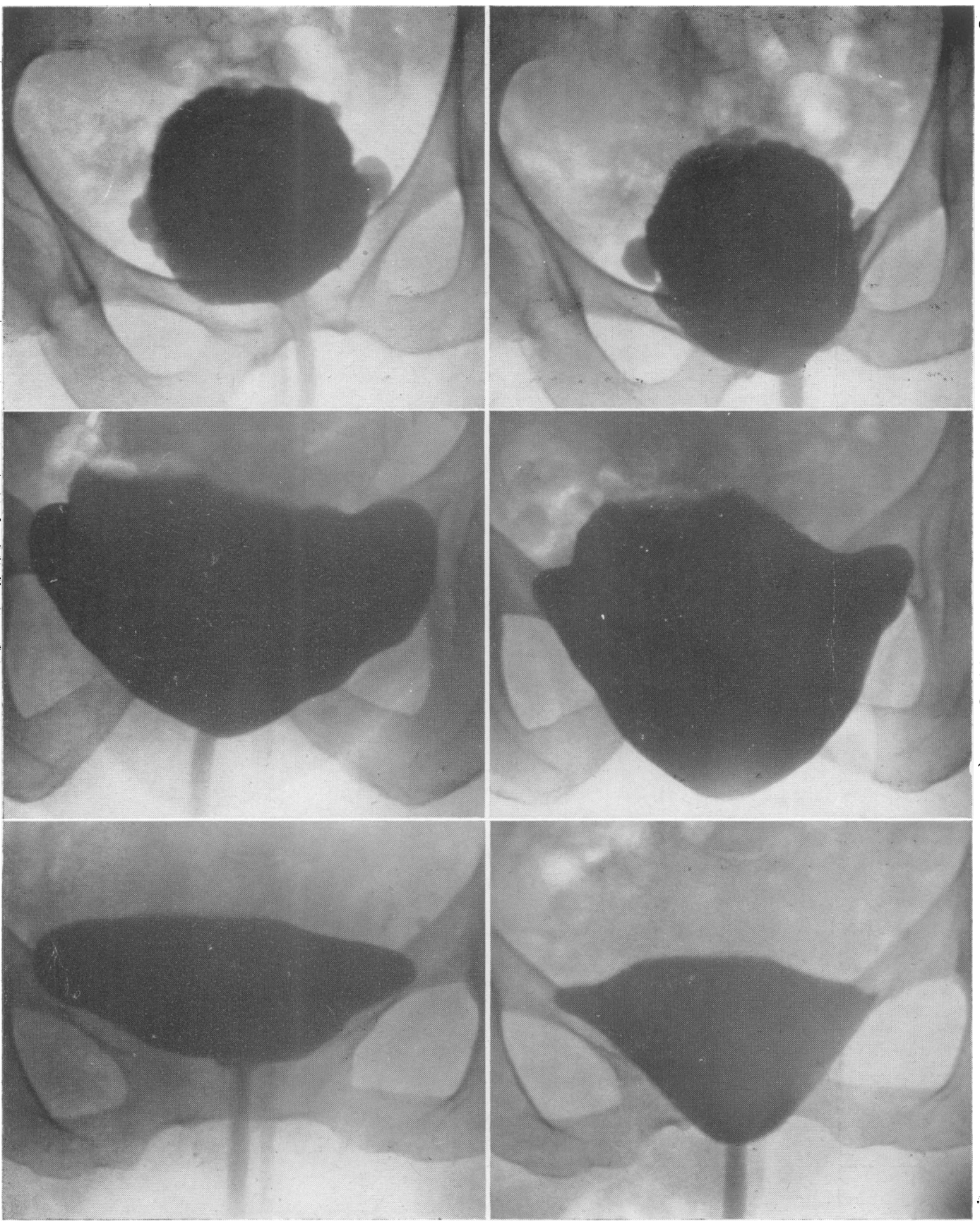

Figs. 7, 8.-Cystograms on separate films of case exhibiting marked stress incontinence despite previous vaginal repair. Compare level of bladder base relative to pubis in the relaxed and straining positions. (Six months' cure by Millin sling.)

Figs. 9, I0.-Cystograms on separate films of case of extreme stress incontinence despite five previous surgical attempts at cure.

FIGs. I I, I 2.- Cystograms on separate films of case of very severe stress incontinence despite Gracilis operation. Following latter procedure there was relief for three months, but the condition relapsed. 



Figs. 1 3, 14.-Cystograms of case shown in Figs. I1, 12 after Millin sling.

FIg. 15.-Tracing of Figs. 13, 14 superimposed. Note fixity of bladder base.

FIG. 17.- Superimposed cystogram showing normal appearance after cure by Millin sling of marked stress incontinence. (Three previous failed vaginal interventions.)
FIG. I6.-Oblique cystogram of same case after sling.

Fig. I 8.-Superimposed cystogram after cure by Millin sling. 


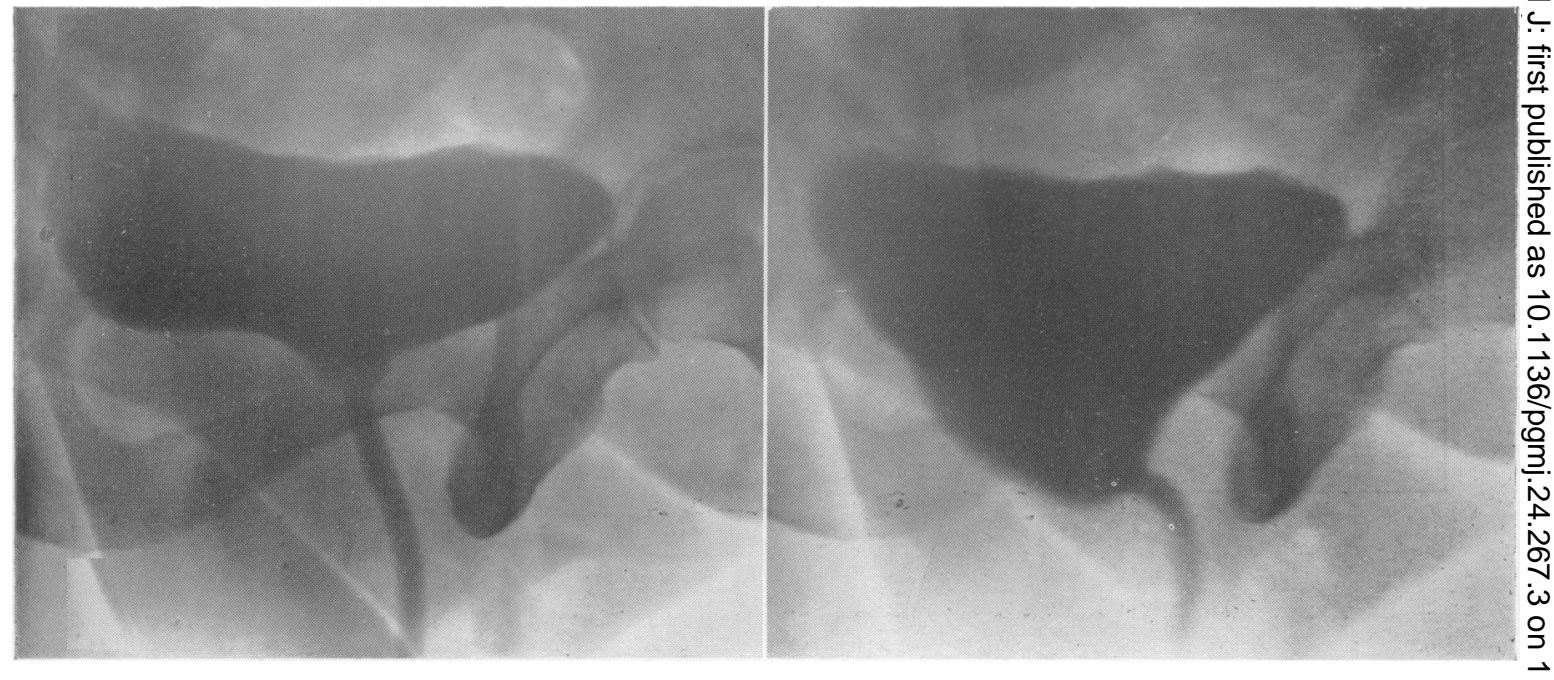

FIGS. 19, 20.-Oblique cystograms in case of marked stress incontinence (two unsuccessful surgical interventions). Note movement of bladder neck downwards and backwards (three cms. on skiagram) on straining.

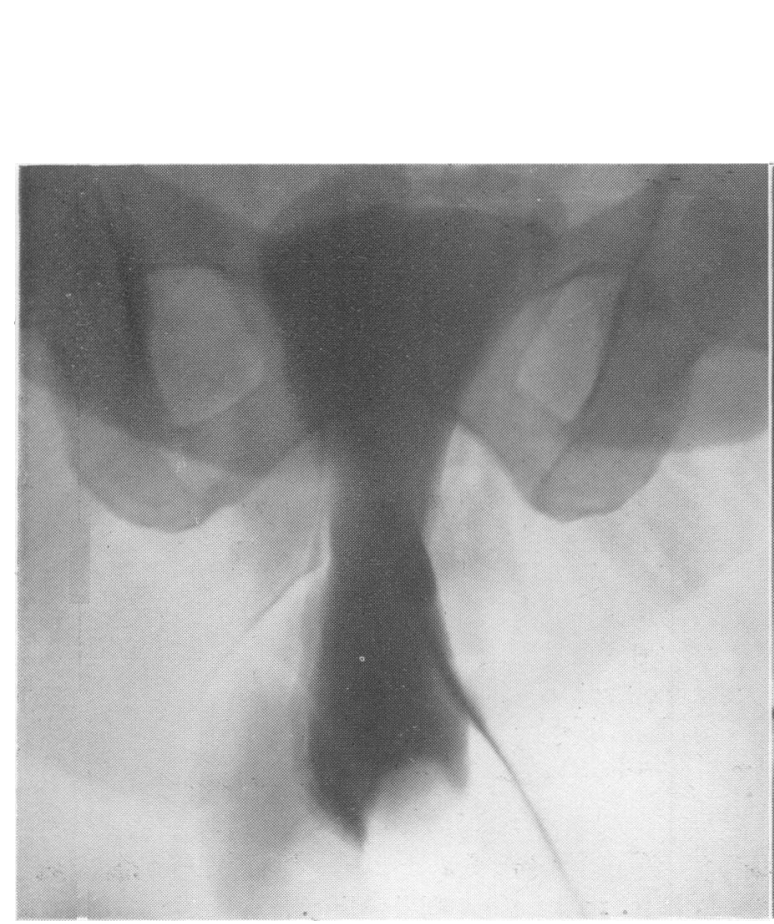

Fig. 21.-A-P shift cystogram in case of markied procidentia without incontinence. (Foley catheter used here, bag being partially distended with Neo-hydriol). Note no downward movement of bladder neck.

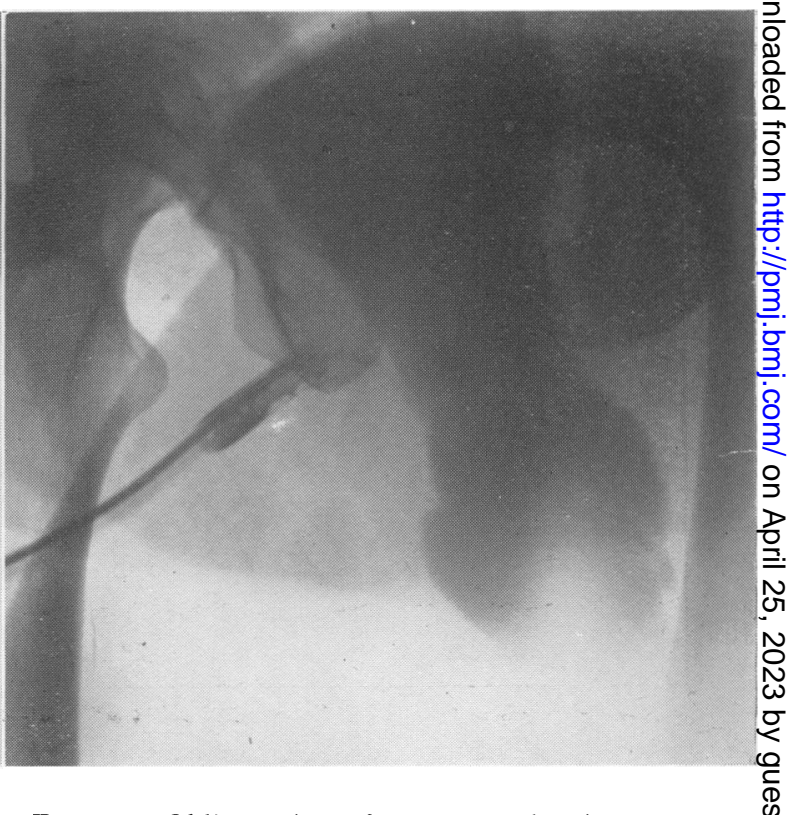

FIG. 22.- Oblique view of same case showing no move- $\stackrel{\oplus}{+}$ ment either downwards or backwards on straining. 7 (Cf. Figs. I9 and 20). 
(2) Gracilis transplant of Giordano.

(3) Anterior plication of Lowsley.

(4) Urethral rotation of Gersuny.

(5) Urethral angulation of Thomsen.

(6) Urethral angulation and elongation of Bonney.

\section{Abdominal Operations}

(I) Cystopexy of Bonney.

(2) Cervico-cystopexy of Perrin and Williams.

(3) Aponeurotic suspension of Goebel, Stoeckel.

(4) Intravesical tautening of bladder neck (Millin, Macky).

(5) Millin sling operation (to be described in detail later).

\section{Combined Abdomino-Vaginal Operations}

(I) Frankenheim, Michon.

(2) Aldridge, Studdiford.

(3) Delinotte.

Undoubtedly the commonest operation employed today is some type of colporrhaphy in association with a buttressing of the tissues below the bladder neck by some form of suture-mattress or otherwise-suitably placed in the sub-urethral tissues. Experience shows that the long-term results are on the whole not so satisfactory as was originally thought. It was commonly stated that the cure rate was over 90 per cent., but in our experience it is certainly much lower than this, and Counsellor has estimated that even in the the best hands the cure rate is not above 70 per cent. We can confirm this. The late recurrence rate is seldom appreciated, and we have seen many patients in whom the immediate result has been completely satisfactory, but with the passage of a few months the symptoms have returned to their original degree of severity. Such patients seldom benefit from a repeat vaginal repair.

The Kelly operation, so ardently supported by the Baltimore School, is, we believe, in some respects based on false premises. Its exponents believe that there is an intrinsic laxity of the sphincter mechanism about the bladder neck, and they 'take a tuck' in the sphincter by means of a silk mattress suture during the performance of the colporrhaphy. One of us (T.M.) has in the past operated upon more than forty of these cases by an intra-vesical technique, and has found, in contradistinction to the cases of congenital incontinence, only rarely, a marked relaxation of the vesical outlet. (This observation would appear to disprove the contention of Macky, and to make his proposed intra-vesical tautening of the 'torn' sphincter unnecessary.)

The operations of Kennedy and Davies are based on the belief that the urethral sphincters are of prime importance. They aim at restoring these structures, but in the course of their operations a wide freeing of the bladder neck and urethra is effected. In Davies' operation the base of the bladder is freed extensively in addition. In both these operations the loss of blood can be considerable. We believe that the good results of these workers and their adherents, notably Counsellor, are due more to the excellence of the buttressing obtainable after the wide freeing of the bladder neck, and only serve to corroborate our view that the essential lesion is a descent of the bladder neck.

The Gracilis transplant proposed by Giordano and advocated by others, notably Loughnane in this country, is based, in our submission, on a false conception of the pathology. Attention is here directed not against the faulty bladder neck, but against the urethra, which it aims at compressing. When the muscle transplant does not slough early, a good immediate result may be obtained, but later the muscle becomes converted into fibrous tissue and the incontinence recurs.

The urethral rotation operation of Gersuny seldom gives satisfactory results and there is a real risk of sloughing of the urethra. We have seen two such cases and the results were disastrous. Recently Thomsen has described a method of acutely angulating the urethra and has shown some urethrograms illustrating both the pre- and post operative findings. We feel that the good resultes obtained by him are again due more to the eleva? tion of the bladder neck than to the urethral angulation in his procedure.

The Lowsley ribbon-gut anterior plication has, in our opinion, little to recommend it.

Recently Wilfred Shaw has advocated the suturing of what he terms the 'post-urethral ligament' to the cervix, thus forming a shelf upon which the bladder rests. This undoubtedly elevates the the bladder neck, but we feel that it tends to approximate the cervix to the symphysis with resulting tendency to retroversion and shortening of the anterior vaginal wall.

\section{Abdominal Operations}

Of the abdominal operations, cystopexy and cervico-cystopexy have been performed by many workers, notably Bonney, Perrin and EverardWilliams. The operation involves a ventrofixation of the bladder, with or without the bladder neck, to the posterior periosteum of the symphysis and to the anterior abdominal wall. Both catgut and silk have been used and it would appear that cervico-cystopexy, using silk, offers the best chance of a cure. We feel that time will eventually show a relaxation of the cervical and bladder musculature with recurrence of the incontinence. Moreover, the use of silk may be followed by a perforation of the mucous membrane with exposure of the 
silk to the urine and subsequent formation of phosphatic encrustations.

The original 'sling' operation proposed by Goebel undoubtedly led to some cures, with improvement in many others, but suspension of the bladder neck from a fixed bony point allows for little margin of error-an unduly tight sling will give rise to a bar formation at the vesical outlet with dysuria or even retention, whilst a failure to elevate sufficiently will not realize a complete relief from symptoms.

One of us (T.M.) for some time practised an intra-vesical operation in which the bladder was opened suprapubically and, after a wedge of the bladder neck had been excised, the outlet was narrowed and buttressed with chromic catgut mattress sutures. The immediate results were on the whole good, but relapses occurred, and the operation was abandoned.

The sling operation (to be discussed in detail in a subsequent article) proposed by Millin more than three years ago, and now carried out by us in more than rzo cases, has been found singularly effective.

\section{Combined Approach}

Frankenheim, Michon, Delinotte, Studdiford and Aldridge have all worked on a combined abdominovaginal approach to the problem and the procedure of Aldridge is perhaps the best known and the most widely practised. This operation in this country has been endorsed by Chassar Moir and it undoubtedly produces good results. It combines an anterior vaginal repair with the application of a fascial sling of external oblique aponeurosis below the urethra. Its performance necessitates $\stackrel{\varnothing}{\circ}$ both an abdominal and a vaginal incision and it is $\varsigma$ relatively time-consuming. It involves alteration $\overrightarrow{\overrightarrow{\vec{S}}}$ of the position of the patient during the operationand has the theoretical risk of sepsis ascending $\frac{}{0}$ from the vaginal incision.

It will be seen from the above consideration $\vec{\partial}$ that many procedures have been proposed and $\varrho$ applied to cure this distressing complaint. The multiplicity of operations suggests that in the past $\vec{O}$ no single method has been completely successful. $\overrightarrow{-}$ We would reiterate that while we consider that $\vec{\sigma}_{\sigma}$ a sling operation of the Aldridge or Millin typez will cure most cases, we feel that the performance 3 of these sling operations is rarely just:fied until an adequate attempt has been made at repair from + the vagina. In our view, in the case of a failedo urethroplasty, the 'Millin sling' operation is that $\omega$ of choice.

\section{BIBLIOGRAPHY}

ALDRIDGE A. H. (1942), Amer. F. Obst. E Gyn., 44, 398 DAVIES, J. W. (1942), Ұ. Uroi., 48, 536

DELINOTTE, R. (1947), F. Belge d'Urol., 6,76r.

KENNEDY, W. T. (1937), Amer. F. Obst.' 'G Gyn., 34, 576 LOWSLEY, O. S. (1936), $\mathcal{F}$. Urol., 36, 400.

MACKY, F. (1944), f. Urol. 52, 27.

MICHON, LOUIS (1946), 39me. Congres franc. d'Urol., p. 340 MILLER, J. D. (1938), F. Urol., 40, 612.

MILLIN, TERENCE (1939), Proc. Roy. Soc Med., xxxii, 777.

MILLIN,' TERENCE (I947), Proc. Roy. Soc. Med., 40, 36I.

MOIR, J.' CHASSER (1947), Edin. Med. Ұ., LIV, 368 .

MUELL NER, S. R. (1946), New Eng. F. Med., 12, 400.

PERRIN, E. (I946), 39me. Congres franc. d'Urol., p. 334.

STUDDIFORD, W. E. (1944), Amer. F. Obst. Eं Gyn., 47, 764.

STUDDIFORD, W. E. (1945), Ibid., 50, I19.

'THOMSEN, EINAR (1940), Acta Radiologica XI, 5, 63.

THOMSEN, EINAR (194I), Acta Radiologica XII, 3, 4, 73, 74.

'Stress Incontinence of Urine in the Female'-Part 2 will be published in the February number of this fournal.

In Great Britain there is strong opposition to the whole concept of a university hospital, an opposition rarely if ever based on first-hand experience of the working of the system in other countries. Nevertheless I remain convinced that the transformation of the teaching hospitals of Great Britain into true university hospitals would do more than any other single act of reform in medical education to ensure that our successors will indeed be members of a liberal scientific and learned profession.

Professor Harry Platt. 1947. 